\title{
Complete Rescue of Cerebrovascular Function in Aged Alzheimer's Disease Transgenic Mice by Antioxidants and Pioglitazone, a Peroxisome Proliferator-Activated Receptor $\gamma$ Agonist
}

\author{
Nektaria Nicolakakis, ${ }^{1}$ Tahar Aboulkassim, ${ }^{1}$ Brice Ongali, ${ }^{1}$ Clotilde Lecrux,${ }^{1}$ Priscilla Fernandes, ${ }^{1}$ Pedro Rosa-Neto, ${ }^{2,3}$ \\ Xin-Kang Tong, ${ }^{1}$ and Edith Hamel ${ }^{1}$ \\ ${ }^{1}$ Laboratory of Cerebrovascular Research, ${ }^{2}$ Brain Imaging Centre, Montréal Neurological Institute, and ${ }^{3}$ Douglas Hospital Research Centre, McGill \\ University, Montréal, Québec, Canada H3A 2B4
}

\begin{abstract}
Accumulating evidence suggests that cerebrovascular dysfunction is an important factor in the pathogenesis of Alzheimer's disease (AD). Using aged ( $\sim 16$ months) amyloid precursor protein (APP) transgenic mice that exhibit increased production of the amyloid- $\beta(\mathrm{A} \beta)$ peptide and severe cerebrovascular and memory deficits, we examined the capacity of in vivo treatments with the antioxidants $\mathrm{N}$-acetylL-cysteine (NAC) and tempol, or the peroxisome proliferator-activated receptor $\gamma$ agonist pioglitazone to rescue cerebrovascular function and selected markers of AD neuropathology. Additionally, we tested the ability of pioglitazone to normalize the impaired increases in cerebral blood flow (CBF) and glucose uptake (CGU) induced by whisker stimulation, and to reverse spatial memory deficits in the Morris water maze. All compounds fully restored cerebrovascular reactivity of isolated cerebral arteries concomitantly with changes in proteins regulating oxidative stress, without reducing brain $\mathrm{A} \beta$ levels or $\mathrm{A} \beta$ plaque load. Pioglitazone, but not NAC, significantly attenuated astroglial activation and improved, albeit nonsignificantly, the reduced cortical cholinergic innervation. Furthermore, pioglitazone completely normalized the CBF and CGU responses to increased neuronal activity, but it failed to improve spatial memory. Our results are the first to demonstrate that late pharmacological intervention with pioglitazone not only overcomes cerebrovascular dysfunction and altered neurometabolic coupling in aged APP mice, but also counteracts cerebral oxidative stress, glial activation, and, partly, cholinergic denervation. Although early or combined therapy may be warranted to improve cognition, these findings unequivocally point to pioglitazone as a most promising strategy for restoring cerebrovascular function and counteracting several AD markers detrimental to neuronal function.
\end{abstract}

Key words: amyloid- $\beta$; PPAR $\gamma$; memory; cholinergic; oxidative stress; cerebral blood vessels

\begin{abstract}
Introduction
Alzheimer's disease $(\mathrm{AD})$ is the most common form of senile dementia, being characterized by high levels of soluble amyloid- $\beta$ $(\mathrm{A} \beta)$ peptide and its deposition in brain (senile plaques) and blood vessels [cerebral amyloid angiopathy (CAA)], neurofibrillary tangles, cerebral oxidative stress, inflammation, and impaired neuronal function and cerebral glucose utilization (CGU) (Cummings, 2004; Mosconi et al., 2004). However, most AD cases feature early decreases in cerebral perfusion (de la Torre,
\end{abstract}

\footnotetext{
Received April 22, 2008; accepted Aug. 9, 2008.

This work was supported by Canadian Institutes of Health Research (CIHR) Grant MOP-62194, the Alzheimer Society of Canada, Takeda Pharmaceuticals, a (IHR studentship (N.N.), and Jeanne Timmins Costello (T.A.) and Fonds de la Recherche en Santé du Québec (B.0.) fellowships. We thank Dr. L. Mucke (Gladstone Institute of Neurological Disease and Department of Neurology, University of California, San Francisco, CA) for the hAPP ${ }_{S_{w}, \text { Ind }}$ transgenic mouse breeders, C. Steriade for serving as a blind observer in SOD2 immunocytochemical data analysis, A. Aliaga for performing the PET scans, and Dr. M. Diksic for data analysis in the repeated-measures ANOVA.

Correspondence should be addressed to Dr. Edith Hamel, Department of Neurology and Neurosurgery, Montréal Neurological Institute, McGill University, Montréal, Québec, Canada H3A 2B4. E-mail: edith.hamel@mcgill.ca. D0I:10.1523/JNEUROSCI.3348-08.2008

Copyright $\odot 2008$ Society for Neuroscience $\quad 0270-6474 / 08 / 289287-10 \$ 15.00 / 0$
}

2004; Zlokovic, 2005) that can stimulate amyloidogenesis (Sun et al., 2006), impair A $\beta$ clearance (Zlokovic, 2005), and disrupt synthesis of proteins crucial for learning and plasticity (Hermann et al., 2001). Accordingly, hypoperfusion can trigger dementia in the vulnerable aging brain (de la Torre et al., 1992; Ruitenberg et al., 2005) or worsen AD outcome (Sun et al., 2006).

Cerebral hypoperfusion may arise as a consequence of peripheral vascular diseases that limit blood supply to the brain, such as hypertension and type 2 diabetes, two major AD risk factors (Girouard and Iadecola, 2006). It may also result from the loss of basalocortical cholinergic innervation (Tong and Hamel, 1999; Auld et al., 2002), which regulates not only mnemonic function, but also cerebral blood flow (CBF) (Hamel, 2004). However, in $\mathrm{A} \beta$-overproducing APP mice, recent evidence suggests that $\mathrm{CBF}$ is primarily compromised by the enhanced generation of NADPH oxidase-derived superoxide $\left(\mathrm{O}_{2}{ }^{-}-\right)$radicals, which interfere with vasoactive molecules and deregulate cerebrovascular function. Indeed, arterial reactivity, neurovascular coupling (the CBF response to neuronal activation) (Iadecola et al., 1999; Niwa et al., 2000; Tong et al., 2005), and cerebral autoregulation are 
severely impaired (Niwa et al., 2002), but remedied in young APP mice by coexpression of APP and the free radical scavenger superoxide dismutase 1 (SOD1), after cortical SOD application (Iadecola et al., 1999) or genetic inactivation of the Nox2 catalytic subunit of NADPH oxidase (Park et al., 2005).

More relevant to $\mathrm{AD}$ therapy, however, is the recovery of vasodilatory function in aged APP mice displaying severe cerebrovascular and memory deficits, hence, best mimicking $\mathrm{AD}$ patients, after incubation of cerebral arteries with the antioxidants SOD or catalase (Tong et al., 2005). Given the normalization of the vascular deficits in vitro, our goal was to test their reversibility in vivo by treating aged APP mice with the blood-brain barrier permeable antioxidants $N$-acetyl-L-cysteine (NAC) and tempol, or the peroxisome proliferator-activated receptor $\gamma(\operatorname{PPAR} \gamma)$ agonist pioglitazone, compounds efficacious against vascular dysfunction associated with hypertension or diabetes. To clarify the mechanisms underlying recovery, we investigated changes in proteins related to oxidative stress and vasomotor function. Additionally, we studied the effects of pioglitazone relative to NAC on classical AD hallmarks (amyloidosis, astrocyte activation, and cholinergic denervation) and, given its potent efficacy, determined its ability to correct the altered neurovascular (CBF) and neurometabolic (CGU) coupling responses to whisker stimulation and to restore memory. The findings demonstrate that late pharmacological intervention with antioxidants and pioglitazone fully restored cerebrovascular function, but that only pioglitazone improved neuronal and astroglial markers of AD, hence positioning it as a most promising therapy for $\mathrm{AD}$-related cerebrovascular deficits and brain dysfunction.

\section{Materials and Methods}

APP transgenic mice (APP mice). Experiments were approved by the Animal Ethics Committee of the Montréal Neurological Institute, and abided by the guidelines of the Canadian Council on Animal Care. We used heterozygous transgenic mice $(\sim 40 \mathrm{~g})$ with a neuronal overexpression of the Swedish $\left(670 / 671_{\mathrm{KM} \rightarrow \mathrm{NL}}\right)$ and Indiana $\left(717_{\mathrm{V} \rightarrow \mathrm{F}}\right)$ mutations of human APP driven by the platelet-derived growth factor $\beta$ promoter on a C57BL/6J background (line J20) (Mucke et al., 2000; Tong et al., 2005). Treatment was initiated at $\sim 14$ months of age, at which time APP mice displayed $\mathrm{A} \beta$ plaques, but limited CAA (Tong et al., 2005), activated glia (Mucke et al., 2000), cholinergic denervation (Aucoin et al., 2005), impaired vascular reactivity (Tong et al., 2005), and cognitive deficits (Palop et al., 2003).

In vivo drug treatments. Mice were treated with NAC $(100 \mathrm{mg} / \mathrm{kg} / \mathrm{d}$, i.p., in PBS, 4 weeks; Sigma-Aldrich) (Farr et al., 2003), tempol (1 mm in drinking water, 6 weeks; Sigma-Aldrich) (Schnackenberg and Wilcox, 1999), or pioglitazone $[20 \mathrm{mg} / \mathrm{kg} / \mathrm{d}$ (Takeda Pharmaceuticals) in Teklad Rodent chow diet \#2019, 6-8 weeks (Research Diets)] (Yan et al., 2003), with half of the wild-type and APP mice in each group receiving vehicle or control diet. Compounds were chosen for their demonstrated efficacy against vascular dysfunction in patients or animal models of hypertension and diabetes (Schnackenberg and Wilcox, 1999, 2001; Cabassi et al., 2001; Diep et al., 2002; Martens et al., 2005). Mice had access to water and food ad libitum, and their body weight was monitored weekly, with no significant change during the course of treatment. In the pioglitazonetreated group, fasting glycemia was measured every 2 weeks (weeks 2-6) from a drop of blood from the tail tip with a commercial glucometer (One Touch Ultra; LifeScan), and there was no drug effect on any of the groups $\left(F_{(2,32)}=1.25 ; p=0.30\right)$.

Vascular and brain tissues. After treatment, mice were killed by cervical dislocation and the reactivity of the middle cerebral artery (MCA) tested (see below), whereas vessels of the circle of Willis and their ramifications (referred to as pial vessels) were removed, frozen on dry ice together with cortex or one hemibrain, and stored $\left(-80^{\circ} \mathrm{C}\right)$ for subsequent protein extraction. The other hemisphere was immersion fixed [overnight, $4^{\circ} \mathrm{C}$, in $4 \%$ paraformaldehyde (PFA) in $0.1 \mathrm{M} \mathrm{PBS,} \mathrm{pH}=7.4$ ], cryoprotected, frozen in isopentane, and stored $\left(-80^{\circ} \mathrm{C}\right)$ until the cutting of $20-\mu \mathrm{m}-$ thick sections on a freezing microtome. For SOD2 immunohistochemistry, additional groups of mice treated with each compound were perfused intracardially (4\% PFA) under deep anesthesia $(65 \mathrm{mg} / \mathrm{kg}$ sodium pentobarbital, i.p.), and the brains processed as above.

Vascular reactivity. The reactivity of pressurized MCA segments was evaluated using on-line videomicroscopy as described previously (Tong et al., 2005). Dilatory responses to acetylcholine (ACh; $10^{-10}-10^{-5} \mathrm{M}$ ) and calcitonin gene-related peptide (CGRP; $10^{-10}-10^{-6} \mathrm{M}$ ) were tested on vessels preconstricted submaximally with serotonin $\left(2 \times 10^{-7} \mathrm{M}\right)$. The tonic production of the vasodilator NO was evaluated in vessels at basal tone by superfusion of the nitric oxide synthase (NOS) inhibitor $\mathrm{N}^{\omega}$-nitro-L-arginine (L-NNA; $10^{-5} \mathrm{M}, 35 \mathrm{~min}$ ). Vessel responses (percentage changes in diameter from preconstricted or basal tone) were plotted as a function of agonist concentration or duration of NOS inhibition. The maximal response $\left(\mathrm{EA}_{\max }\right)$ and the concentration eliciting half of the $\mathrm{EA}_{\max }\left(\mathrm{EC}_{50}\right.$ value or $\left.\mathrm{pD}_{2}=-\left[\log \mathrm{EC}_{50}\right]\right)$ were used to determine agonist efficacy and potency, respectively.

Western blot. Proteins were quantified by Western blot in pial vessels and cerebral cortex of the same animals used in the vascular reactivity studies, $\beta$-site APP-cleaving enzyme 1 (BACE1) and total soluble A $\beta$ being measured only in cortex for all treatments [for details, see the study by Tong et al. (2005), except for $A \beta$, detected with tricine- rather than glycine-SDS gels]. Membranes loaded with proteins $(4-20 \mu \mathrm{g})$ were incubated with either rabbit anti-SOD1 [1:3000 (vessels)/1:10,000 (cortex); Stressgen], anti-SOD2 (1:20,000/1:10,000; Stressgen), anti-APP (1: 2000/1:500; ProSci), anti-BACE1 (1:1000, Santa Cruz Biotechnology), mouse anti-endothelial NOS (eNOS; 1:500; BD Biosciences Transduction Laboratories), anti-cyclooxygenase-2 (COX-2; 1:200/1:100; Cayman), anti-p67 ${ }^{\text {phox }}$ (1:200; BD Biosciences Transduction Laboratories), anti-A $\beta$ (6E10, 1:1000/1:200; BioSource International), or anti-actin (1: 10,000 , Sigma), which was used to normalize loading variation. Blots were incubated $(1 \mathrm{~h})$ with horseradish peroxidase-conjugated secondary antibodies (1:2000; Jackson ImmunoResearch), and proteins visualized with enhanced chemiluminescence (ECL Plus kit; GE Healthcare) using PhosphorImager (Scanner STORM 860; GE Healthcare), followed by densitometric quantification with ImageQuant 5.0 (Molecular Dynamics).

ELISA measurement of $A \beta$. In addition to Western blot analysis of total soluble $\mathrm{A} \beta$ in cortex, soluble and insoluble $\mathrm{A} \beta_{1-40}$ and $\mathrm{A} \beta_{1-42}$ were measured in the pioglitazone-treated group using an ELISA-based assay. Hemibrains were homogenized by sonication (20 s) in 20 mм Tris buffer containing $1 \mathrm{~mm}$ EDTA, $1 \mathrm{~mm}$ EGTA, $250 \mathrm{~mm}$ sucrose, and protease inhibitors. Soluble $A \beta$ was extracted by centrifugation $(100,000 \times g, 60$ $\left.\mathrm{min}, 4^{\circ} \mathrm{C}\right)$ using diethyl acetate $(0.4 \%$ in $10 \mathrm{~mm} \mathrm{NaCl})$ (Elder et al., 2007). The pellet containing insoluble $\mathrm{A} \beta$ was sonicated $(20 \mathrm{~s})$ in $70 \%$ formic acid (FA), centrifuged as above (30 $\mathrm{min})$, and the FA extract neutralized by a 1:15 dilution in Tris-phosphate neutralizing buffer. Soluble and insoluble $\mathrm{A} \beta_{1-40}$ and $\mathrm{A} \beta_{1-42}$ levels were measured by ELISA as described by the manufacturer (BioSource International), and results expressed as nanomoles per gram of protein in the supernatant or FA-soluble fraction.

Histochemistry and immunohistochemistry. Mature, dense-core amyloid plaques in brain sections were stained ( $8 \mathrm{~min}$ ) with $1 \%$ thioflavine $\mathrm{S}$ (Tong et al., 2005) observed under a Leitz Aristoplan light microscope equipped with epifluorescence using an FITC filter (Leica), and pictures acquired with a digital camera (Coolpix 4500; Nikon). Diffuse and mature $\mathrm{A} \beta$ plaques were also immunodetected with an antibody against $\mathrm{A} \beta_{1-42}$. For immunohistochemistry, brain sections were treated with $2 \%$ $\mathrm{H}_{2} \mathrm{O}_{2}$ (except for SOD2) and incubated overnight at room temperature with rabbit anti-A $\beta_{1-42}$ (1:800; BioSource International), anti-SOD2 (1: 400; Stressgen), anti-glial fibrillary acidic protein (GFAP, a marker of astrocyte activation; 1:1000; DAKO), or goat anti-choline acetyltransferase (ChAT; 1:250; Millipore). GFAP and ChAT were detected by immunofluorescence with cyanin 2 (Cy2)- and Cy3-conjugated secondary antibodies (1:400; Jackson ImmunoResearch) and observed under epifluorescence light microscopy and confocal microscopy (Zeiss LSM 510, emission intensity at $543 \mathrm{~nm}$ ), respectively. For SOD2 and A $\beta_{1-42}$ immunostaining, sections were incubated with biotinylated IgG (1h, 30 
min; Vector Laboratories) followed by the avidin-biotin complex (1h, 15 min; ABC kit, Vectastain Elite, Vector Laboratories) and the reaction visualized with the slate gray (SG) reagent (SOD2, Vector SG kit, gray precipitate) or $0.05 \% 3,3^{\prime}$-diaminobenzidine (DAB; $\mathrm{A} \beta_{1-42}$, brown precipitate; Vector Laboratories). Double-immunodetection of cholinergic terminals and $\mathrm{A} \beta$ plaques was performed with ChAT immunostained with $\mathrm{DAB}$, followed by $\mathrm{A} \beta_{1-42}$ in the second position using SG. Primary antibodies were omitted in some sections to control for labeling specificity.

Quantification of staining. Digital images (two to three sections per mouse, three to six mice per group) taken under the same conditions were analyzed with the MetaMorph 6.1r3 software (Universal Imaging). The areas of interest (cingulate and somatosensory cortex, hippocampus) containing thioflavine S-, $\mathrm{A} \beta_{1-42^{-}}$, and GFAP-positive elements were manually outlined in low power images. High-power confocal microscope images of layers II to IV of the somatosensory cortex were used for quantification of ChAT-immunoreactive fibers (cell bodies were manually excluded). The number and/or area occupied by thioflavine $\mathrm{S}$ and $\mathrm{A} \beta_{1-42}$-positive plaques, GFAP-positive astrocytes, and ChAT fibers were quantified and expressed as number or surface area occupied in the delineated areas of interest. The number of $\mathrm{A} \beta_{1-42}$ plaques with swollen ChAT terminals was counted under the microscope in doubleimmunostained sections of pioglitazone-treated and untreated APP mice. Cortical SOD2 immunoreactivity was semiquantitatively analyzed by two independent observers, one totally blind to the identity of the sections. The intensity of neuronal and parenchymal SOD2 staining was assigned scores (light, 1; medium, 2; dark, 3) by each observer; these were pooled and averaged for each mouse.

Morris water maze. A group of pioglitazone-treated mice and their controls was tested for 5 consecutive days in a circular pool $(1.4 \mathrm{~m}$ in diameter) filled with water $\left(25^{\circ} \mathrm{C}\right.$, clouded with powdered skim milk) and containing a transparent platform $(15 \mathrm{~cm}$ in diameter) submerged 1 $\mathrm{cm}$ below the water surface in the center of the northwest quadrant (Morris, 1984; Brouillette and Quirion, 2008). Mice were randomly started from each of three positions (south, east, and north) and used visuospatial cues to find the hidden platform that remained in the same quadrant throughout testing, their movements being followed and analyzed with the 2020 Plus tracking system and Water 2020 software (Ganz FC62D video camera; HVS Image). Mice were given three trials of $90 \mathrm{~s}$ to find the platform (maximum intertrial interval, $45 \mathrm{~min}$ ), being guided to and allowed to stay on it for $5 \mathrm{~s}$ on the first day if they exceeded the allotted time. Escape latencies from the three start points were averaged and used to plot a learning curve. A probe trial of $60 \mathrm{~s}$ was given on day 5 ( $2 \mathrm{~h}$ after the hidden platform trials) and the time spent and distance traveled in the quadrant where the platform was previously located were recorded, along with swim speed. To control for differences in visual acuity or motivation to escape, mice that failed to escape onto a visible platform (cue trial) in both of two trials were excluded. Animals were allowed to dry under a heating lamp after each trial to avoid hypothermia, and all experiments were started at the same time every day. Levels of serum corticosterone, a stress-induced glucocorticoid known to impair memory (Moosavi et al., 2007), were measured after the animals were killed at the end of in vivo studies using the Correlate-EIA Corticosterone Enzyme Immunoassay kit (Assay Designs).

$\left[{ }^{18} \mathrm{~F}\right] F D G-P E T$. A subset of mice tested in the water maze were scanned for cerebral uptake of 2-deoxy-2-[ $\left.{ }^{18} \mathrm{~F}\right]$ fluoro-D-glucose ( $\left.\left[{ }^{18} \mathrm{~F}\right] \mathrm{FDG}\right)$ under isoflurane sedation (1-2\% in medical air) in an R4 microPET scanner (Siemens Preclinical Solutions). Because pioglitazone-treated wild-type mice did not differ relative to untreated littermates in virtually all variables tested, they were excluded from subsequent positron emission tomography (PET) scan and laser Doppler flowmetry experiments (see below). After a bolus injection of $100-150 \mu \mathrm{Ci}(100 \mu \mathrm{l})$ of [ $\left.{ }^{18} \mathrm{~F}\right] \mathrm{FDG}$ into the tail vein, mice underwent 45 min of continuous whisker stimulation $(8-10 \mathrm{~Hz})$ followed by $25 \mathrm{~min}$ PET acquisition ( $15 \mathrm{~min}$ emission/10 min transmission scan using a $\left[{ }^{57} \mathrm{Co}\right]$ point source). Mice were kept warm with a heating lamp and physiological parameters maintained stable throughout the procedure through online monitoring of cardiac rate, respiration, and temperature (Biopack). Fasting glycemia was measured before scanning and groups were comparable. Functional metabolic im- ages were reconstructed using a maximum a posteriori probability algorithm (Kornblum et al., 2000) and coregistered manually to the C57BL/6J mouse high-resolution structural MRI map (Chen et al., 2006). Volumes of interest (VOIs; $2 \mathrm{~mm}^{2}$ ) were applied on the maximally activated somatosensory cortex (contralateral to the whisker stimulation) and on the analogous area of the ipsilateral cortex (Kornblum et al., 2000). The magnitude of activation was expressed as the ratio of the $\left[{ }^{18} \mathrm{~F}\right] \mathrm{FDG}$ standard uptake value (SUV) in the contralateral relative to the ipsilateral cortex.

Laser Doppler flowmetry. After FDG-PET, mice were allowed to recover for at least $24 \mathrm{~h}$ before undergoing surgery for laser Doppler flowmetry measurement of CBF (Transonic Systems). Anesthetized mice (ketamine, $80 \mathrm{mg} / \mathrm{kg}$, i.p.; Wyeth) were fixed in a stereotaxic frame and the bone over the barrel cortex was thinned to translucency using a dental drill. Body temperature was maintained at $37^{\circ} \mathrm{C}$ using a heating pad. Changes in CBF before, during, and after whisker stimulation $(20 \mathrm{~s}$ at $8-10 \mathrm{~Hz}$ ) were recorded, with four to six recordings acquired every $30-40 \mathrm{~s}$ and averaged for each mouse. Cortical CBF change was expressed as percentage increase relative to baseline. The entire procedure lasted $<75$ min per mouse. At the end of testing, the vascular reactivity of arteries from a subset of mice was tested as described above, and the relationship between responses of individual arteries and CBF changes was analyzed with the Pearson correlation coefficient.

Statistical analysis. Data are expressed as means \pm SEM. Blood glucose levels were compared by repeated-measures ANOVA (Statistica 7.1; StatSoft). All other comparisons were analyzed by one-way ANOVA followed by Newman-Keuls post hoc multiple comparison test or by Student's $t$ test for two-group comparisons (GraphPad Prism 4). A $p<0.05$ was taken as significant.

\section{Results \\ Normalization of cerebrovascular reactivity and the endogenous antioxidant enzyme SOD2}

In agreement with our previous studies in aged APP mice (Tong et al., 2005), cerebral arteries from 16-month-old transgenic animals featured significantly decreased dilatory responses to ACh and CGRP over a wide range of agonist concentrations, with an approximate $50 \%$ reduction in $\mathrm{EA}_{\max }$ compared with wild-type mice (Fig. 1A) (some APP arteries even constricted to CGRP) (Tables 1-3). They also displayed a reduced basal production of $\mathrm{NO}$ as exemplified by the attenuated diameter decrease during NOS inhibition with L-NNA ( $-20 \%$, significant only in the pioglitazone group, likely reflecting interlitter variability in basal NO production) (Tables 1-3). Despite these important decreases in vascular reactivity, there was no overall change in ACh and CGRP potency at vascular receptors, mean $\mathrm{pD}_{2}$ values being comparable between wild-type and transgenic mice (ACh: wild-type, $8.27 \pm$ 0.19 vs APP, $8.70 \pm 0.24$; CGRP: wild-type, $8.76 \pm 0.10$ vs APP, $8.95 \pm 0.15$ ) (Tables $1-3$ ). After in vivo therapy with NAC, tempol, or pioglitazone, impaired cerebrovascular reactivity of APP mice was completely normalized, with dose-dependent and maximal responses as well as agonist potencies being identical to those of wild-type littermates. The treatments did not affect cerebrovascular reactivity of wild-type animals, with no difference between responses of cerebral arteries from untreated and treated controls (Fig. 1A, Tables 1-3).

Quantification of proteins involved in oxidative stress regulation (SOD1, SOD2, p67 ${ }^{\text {phox }}$ ) and synthesis of vasodilator molecules (eNOS, COX-2) confirmed the SOD2 upregulation in cerebral vessels of APP mice (Tong et al., 2005), supporting oxidative stress as the culprit of the functional deficits, and particularly $\mathrm{O}_{2}{ }^{-}$- radicals known to upregulate the mitochondrial SOD2 antioxidant enzyme (Wong and Goeddel, 1998). The SOD2 increase was completely reversed in pioglitazone- (Fig. $1 \mathrm{~B}$ ), but not significantly in NAC- or tempol-treated APP mice (data not shown), an effect possibly attributable to the unique ability of 
pioglitazone to regulate gene transcription, hence, either directly suppressing SOD2 expression or that of SOD2inducing cytokines, such as tumor necrosis factor- $\alpha$ (Wong and Goeddel, 1988; Heneka et al., 2007). There was no significant increase in SOD2 protein levels in the cerebral cortex of APP mice by Western blotting. However, microscopic examination of SOD2 immunoreactivity revealed increased staining intensity in cortical neurons $(+37.8 \pm 5.4 \% ; p<0.05)$ and throughout the neuropil $(+43.5 \pm 12.9 \%$; $p=0.05)$. Although the bulk of enzyme immunostaining within neurons was mostly unaffected, all treatments attenuated SOD2 immunoreactivity throughout the cortical parenchyma (Fig. 1C) (mean scores: wild-type, $1.52 \pm 0.18$; APP, $2.14 \pm$ 0.08 ; treated APP, $1.17 \pm 0.09$; APP vs treated APP, $p<0.01$ ). The apparent discrepancy in the efficacy of tempol and NAC in attenuating SOD2 in brain tissue but not in vessels remains unexplained, but could be related to differences in the cytokines released by vascular versus brain cells, as not all cytokines are capable of inducing SOD2 (Wong and Goeddel, 1988).

\section{Treatment effect on amyloidosis, astrocyte activation and cholinergic denervation}

Transgenic APP mice had increased levels of APP in both pial vessels and cortex, as well as increased brain levels of total soluble $\mathrm{A} \beta$ and soluble and insoluble $\mathrm{A} \beta_{1-40}$ and $A \beta_{1-42}$, whereas levels of the $\beta$-site APP cleaving enzyme BACE1, rate limiting in the production of $A \beta$, were unchanged compared with wild-type mice. These protein levels were not affected by NAC or pioglitazone treatment (Fig. $2 A$ ). High levels of $\mathrm{A} \beta$ translated to extensive $\mathrm{A} \beta$ plaque deposition in the cortex and hippocampus of aged APP mice, as evidenced by both thioflavine $\mathrm{S}$ and $\mathrm{A} \beta_{1-42}$ immunostaining. Neither $\mathrm{A} \beta$ plaque number nor plaque load in the cerebral cortex and hippocampus was reduced by NAC or pioglitazone treatment (Fig. $2 B$ ).

Another hallmark of APP mice and AD brains is an increased inflammatory response characterized by activated microglia and reactive astrocytes (Heneka et al., 2005). This could have a deleterious impact on brain function as the latter control synaptic transmission and neurovascular coupling (Haydon and Carmignoto, 2006), specifically, the CBF response to sensory stimulation (Zonta et al., 2003). Accordingly, APP mice exhibited many islets of activated GFAP-positive astrocytes in the entire cortex, and a continuous stretch of GFAP immunoreactivity in the hippocampus (Fig. 3). This was in contrast with wild-type mice, which seldom featured small regions of astrocyte activation. NAC had no effect on the percentage of cortical area immunopositive for GFAP, but pioglitazone significantly attenuated glial activation in the cortex by almost $50 \%$ in both treated APP and wildtype mice relative to their untreated counterparts (Fig. 3). These findings not only confirm previous reports on the efficacy of $\operatorname{PPAR} \gamma$ agonists in reducing inflammation and the associated
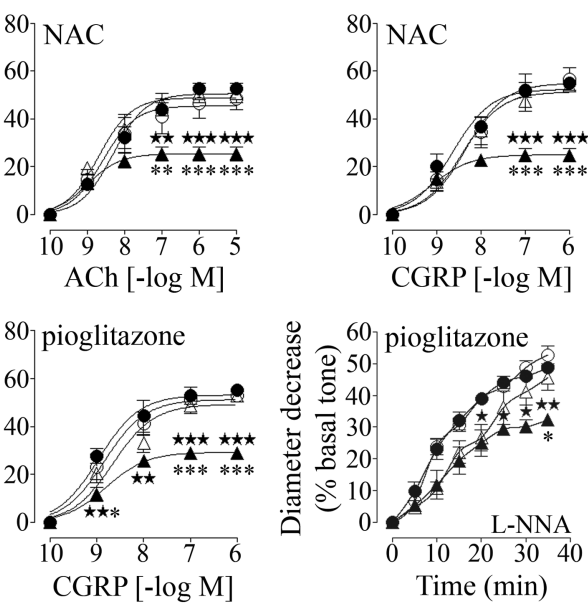

$\mathrm{C}$

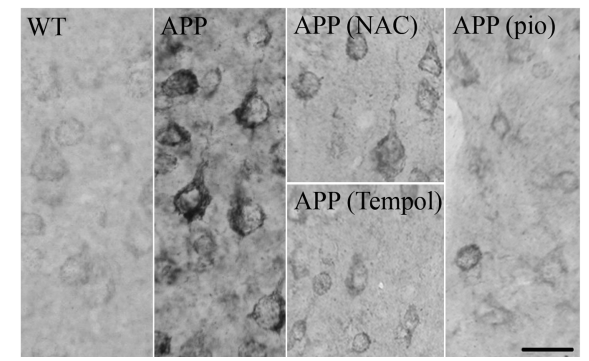

Figure 1. Improved cerebrovascular reactivity coincides with alterations in oxidative stress regulation. $\boldsymbol{A}$, The responses of mice, whereas they were unaffected in treated wild-type $(\bigcirc)$ mice (untreated vs treated APP mice, ${ }^{*} p<0.05,{ }^{* *} p<0.01$,

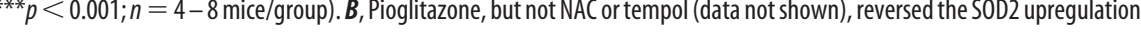
ected by Western blot in pial vessels of APP mice. Actin was used to normalize loading variation ( $n=5-7$ mice/group). $C$, All compounds attenuated the increased SOD2 immunoreactivity detected throughout the cortical neuropil of APP mice, but not the bulk of enzyme immunointensity in neuronal cell bodies ( $n=3-5$ mice/group). Scale bar, $20 \mu \mathrm{m}$. Error bars represent SEM.

glial cell activation (Heneka et al., 2007); they further suggest a protective effect of pioglitazone on the functional neurogliovascular unit that regulates cortical perfusion (Hamel, 2006).

Aged APP mice displayed significantly fewer cholinergic nerve fibers $(-32.0 \pm 4.6 \% ; p<0.05)$ in the somatosensory cortex compared with wild-type littermates. Whereas NAC had no beneficial effect, pioglitazone treatment rescued the number of cortical ChAT-positive fibers by $60.4 \pm 9.5 \%$, although this did not reach statistical significance (Fig. $4 A$ ). Similarly, pioglitazone slightly but nonsignificantly decreased the proportion of $\mathrm{A} \beta$ plaques surrounded by swollen and dystrophic ChAT terminals (Fig. $4 B$ ), indicating that pioglitazone exerted some beneficial effects on both the diffuse, selective cholinotoxicity induced by soluble $\mathrm{A} \beta$ as well as on the focal, nonselective plaque-associated neurotoxicity (Aucoin et al., 2005).

\section{Effect of pioglitazone on cerebral glucose metabolism,} perfusion, and spatial memory

The CBF response to increased neuronal activity that ensures adequate oxygen and glucose supply to activated brain areas is impaired early in APP mice (Niwa et al., 2000), compromising homeostasis between energy demand and substrate delivery, and exacerbating neuronal dysfunction. Moreover, in aged APP mice, the CGU increase after whisker stimulation was reduced compared with wild-type littermates (activation ratio: APP, $1.02 \pm$ 
Table 1. Effects of tempol on cerebrovascular responses to ACh, CGRP, and nitric oxide synthase inhibition with L-NNA

\begin{tabular}{lllll}
\hline Tempol & WT $(n=8)$ & WT (tempol) $(n=6)$ & APP $(n=4)$ & APP (tempol) $(n=5)$ \\
\hline$A C h\left(E A_{\text {max }}\right)$ & $55.5 \pm 5.3$ & $52.6 \pm 5.0$ & $21.7 \pm 3.6^{\star \star}$ & $50.5 \pm 6.8^{*}$ \\
$A C h\left(p D_{2}\right)$ & $8.58 \pm 0.21$ & $8.25 \pm 0.16$ & $8.22 \pm 0.22$ & $7.95 \pm 0.20$ \\
CGRP $\left(E A_{\text {max }}\right)$ & $43.9 \pm 5.3^{a}$ & $50.1 \pm 3.2^{b}$ & $-0.3 \pm 6.6^{\star \star \star}$ & $19.5 \pm 7.1$ \\
CGRP $\left(\mathrm{pD}_{2}\right)$ & $8.69 \pm 0.22$ & $8.96 \pm 0.15$ & ND & $8.88 \pm 0.47$ \\
L-NNA $\left(E A_{\text {max }}\right)$ & $49.0 \pm 5.3$ & $51.5 \pm 5.9$ & $42.7 \pm 3.5$ & $65.7 \pm 5.1^{* \star}$ \\
\hline
\end{tabular}

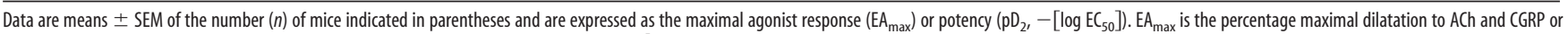
percentage maximal diameter decrease after 35 min inhibition of nitric oxide synthase with $10^{-5} \mathrm{M} \mathrm{L}$-NNA. WT, Wild-type; ND, not determined.

${ }^{a} n=7$.

${ }^{b} n=5$.

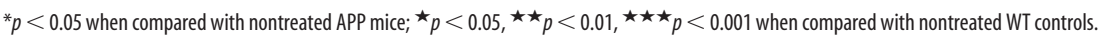

Table 2. Effects of NAC on cerebrovascular responses to ACh, CGRP, and nitric oxide synthase inhibition with L-NNA

\begin{tabular}{lllll}
\hline NAC & WT $(n=5)$ & WT $(\mathrm{NAC})(n=4)$ & APP $(n=5)$ & APP (NAC) $(n=5)$ \\
\hline ACh $\left(E A_{\text {max }}\right)$ & $52.8 \pm 1.4$ & $48.5 \pm 4.5$ & $25.4 \pm 3.0^{\star \star \star}$ & $50.9 \pm 4.1^{* * *}$ \\
ACh $\left(\mathrm{pD}_{2}\right)$ & $8.31 \pm 0.09$ & $8.58 \pm 0.21$ & $8.99 \pm 0.17^{\star}$ & $8.69 \pm 0.13$ \\
$\mathrm{CGRP}\left(\mathrm{EA}_{\max }\right)$ & $54.9 \pm 2.2$ & $56.7 \pm 4.7$ & $24.8 \pm 2.8^{\star \star \star}$ & $54.0 \pm 1.7^{* * *}$ \\
CGRP $\left(\mathrm{pD}_{2}\right)$ & $8.64 \pm 0.12$ & $8.34 \pm 0.17$ & $9.10 \pm 0.16^{\star}$ & $8.42 \pm 0.14^{*}$ \\
$\mathrm{~L}-\mathrm{NNA}\left(\mathrm{EA}_{\max }\right)$ & $45.5 \pm 2.0$ & $50.6 \pm 8.7$ & $34.9 \pm 3.2$ & $48.0 \pm 1.2$ \\
\hline
\end{tabular}

Data are means $\pm S E M$ of the number of mice indicated in parentheses and are expressed as the $\mathrm{EA}_{\max }$ or $\mathrm{pD} \mathrm{D}_{2}$ as described in Table 1. WT, Wild-type.

${ }^{*} p<0.05,{ }^{* * *} p<0.001$ when compared with nontreated APP mice; ${ }^{\star} p<0.05,{ }^{\star \star \star} p<0.001$ when compared with nontreated WT controls.

Table 3. Effects of pioglitazone on cerebrovascular responses to ACh, CGRP, and nitric oxide synthase inhibition with L-NNA

\begin{tabular}{lllll}
\hline Pioglitazone & WT $(n=5)$ & WT (pio) $(n=5)$ & APP $(n=5)$ & APP (pio) $(n=7)$ \\
\hline ACh $\left(E A_{\text {max }}\right)$ & $55.5 \pm 1.6$ & $56.4 \pm 2.3$ & $31.7 \pm 2.3^{\star \star \star}$ & $60.2 \pm 5.4^{* * *}$ \\
ACh $\left(\mathrm{pD}_{2}\right)$ & $7.92 \pm 0.10$ & $8.34 \pm 0.09$ & $8.88 \pm 0.14^{\star}$ & $8.64 \pm 0.15$ \\
CGRP $\left(\mathrm{EA}_{\max }\right)$ & $55.1 \pm 2.2$ & $53.0 \pm 1.4$ & $28.9 \pm 1.4^{\star \star \star}$ & $52.9 \pm 1.1^{* * *}$ \\
CGRP $\left(\mathrm{pD}_{2}\right)$ & $8.95 \pm 0.13$ & $8.83 \pm 0.11$ & $8.80 \pm 0.11$ & $8.65 \pm 0.12$ \\
$\mathrm{~L}-\mathrm{NNA}\left(\mathrm{EA}_{\max }\right)$ & $48.7 \pm 1.6$ & $52.8 \pm 2.8$ & $32.4 \pm 1.9^{\star \star}$ & $45.6 \pm 3.9^{*}$ \\
\hline
\end{tabular}

Data are means \pm SEM of the number of mice indicated in parentheses and are expressed as the $\mathrm{EA}_{\max }$ or $\mathrm{pD}_{2}$ as described in Table 1. WT, Wild-type; pio, pioglitazone.

${ }^{*} p<0.05,{ }^{* * *} p<0.001$ when compared with nontreated APP mice; ${ }^{\star} p<0.05,{ }^{\star \star} p<0.01,{ }^{\star}{ }^{\star}{ }_{p}<0.001$ when compared with nontreated WT controls.

0.01 vs wild-type, $1.08 \pm 0.02 ; p<0.05$ ) (Fig. $5 A$ ), the latter having a magnitude of activation consistent with that reported for the rat using a similar imaging method (Kornblum et al., 2000). Pioglitazone significantly improved the CGU response in treated APP mice (activation ratio, $1.07 \pm 0.01$ ), rendering it comparable with that of wild-type controls (Fig. $5 A$ ).

To test whether recovery of cerebrovascular reactivity in isolated arteries translated in vivo into restored perfusion, the neurovascular coupling response to whisker stimulation was measured in the same group of pioglitazone-treated mice. Indisputably, the decreased stimulus-induced $\mathrm{CBF}$ response $(-42 \%$; $p<0.001)$ in aged APP mice relative to wild-type controls was normalized by pioglitazone (Fig. $5 B$ ). What is more, the recovery of vasodilatory responses to ACh and CGRP in individual arteries was significantly and positively correlated to the stimulus-evoked CBF increase measured in individual mice (Fig. $5 C)$. These findings clearly show that impaired cerebrovascular reactivity measured in vitro is a valid surrogate marker for incapacitated cerebrovascular function in vivo.

Aged APP mice were severely impaired in the Morris water maze, displaying significantly higher escape latencies to locate the hidden platform and decreased time and traveling distance in the target quadrant during the removed-platform probe trial compared with wild-type littermates (Fig. 6). Physical or visual incapacity to reach the platform was ruled out as all mice showed similar swim speeds and found the visible platform in the cue trial (Fig. 6). Administration of pioglitazone did not improve performance of either treated wild-type or APP mice. The nonsignificant trend for higher serum corticosterone levels in APP mice
(4592 $\pm 756 \mathrm{pg} / \mathrm{ml}$ vs wild-type, $2712 \pm 274 \mathrm{pg} / \mathrm{ml}$ ) and their reduction by pioglitazone (treated APP, $2543 \pm 625 \mathrm{pg} / \mathrm{ml}$ ) had no impact on the performance of APP mice, arguing against stress as a major determinant in the memory deficit.

\section{Discussion}

The present results demonstrate that cerebrovascular dysfunction in aged APP mice can be fully rescued by antioxidants and pioglitazone despite persisting amyloidosis and, furthermore, that pioglitazone acted favorably on astrogliosis, cholinergic denervation, and neurometabolic coupling notwithstanding the well-established cognitive deficits.

\section{Cerebrovascular dysfunction and oxidative stress}

A most remarkable outcome from the present study was that the antioxidants NAC and tempol, as well as the PPAR $\gamma$ agonist pioglitazone completely normalized cerebrovascular reactivity in aged APP mice. Given that reactivity is already impaired in 4-month-old APP animals that have no plaques (Tong et al., 2005), and that vessels tested here from aged mice display minimal CAA and were all equally affected (Tong et al., 2005; present study), the cerebrovascular dysfunctions can be imputed to soluble $\mathrm{A} \beta$, as reported in other APP mouse models (Niwa et al., 2002; Beckman et al., 2003). In addition, the reversibility of the deficits, unaltered eNOS protein levels, and overall comparable agonist potencies among groups allow us to discount permanent defects in vessel function, NO-synthesizing potential, or dilatory ACh and CGRP receptors. Recent evidence indicates that the main deleterious molecule in the vascular dysfunctions of APP 
mice is NADPH oxidase-derived $\mathrm{O}_{2}{ }^{-}-$. Indeed, blocking enzyme assembly with apocynin or knocking out the Nox2 catalytic subunit restored dilatory function in $>15$ month-old APP mice (Hamel et al., 2008; Park et al., 2008). Hence, tempol and NAC likely achieved functional recovery through their respective ability to convert $\mathrm{O}_{2}{ }^{\cdot}-$ to $\mathrm{H}_{2} \mathrm{O}_{2}$ and replenish the glutathione substrate of $\mathrm{H}_{2} \mathrm{O}_{2}$-eliminating glutathione peroxidase (Schnackenberg and Wilcox, 1999; Farr et al., 2003), thereby protecting $\mathrm{NO}$ from degradation by $\mathrm{O}_{2}{ }^{-}-$ and preserving its role in vessel tone regulation and ACh- and CGRP-mediated dilatations (Kitazono et al., 2003; Andresen et al., 2006). The latter may also have been restored through the protection from free radicals of ATP-sensitive $\mathrm{K}^{+}\left(\mathrm{K}_{\mathrm{ATP}}\right)$ channels, which mediate several dilatory responses, including those to CGRP (Kitazono et al., 1993; DeWitt et al., 2001).

PPAR $\gamma$ agonists similarly increase NO bioavailability by suppressing expression and/or activity of NADPH oxidase or enhancing that of the antioxidant enzyme SOD1 (Inoue et al., 2001; Hwang et al., 2007), thereby attenuating $\mathrm{O}_{2}{ }^{\circ}-$ production or enhancing its removal. This could explain functional recovery and normalization of SOD2 levels in vessels from pioglitazone-treated mice. The fact that vascular levels of the activity-regulating p $67^{\text {phox }}$ subunit of NADPH oxidase were unaltered in untreated APP mice and those receiving pioglitazone suggests effects on enzyme activity, as reported for rosiglitazone, another PPAR $\gamma$ agonist, in coronary arteries of diabetic mice (Bagi et al., 2004). The normalization of SOD2 immunoreactivity induced by all compounds in the cortical neuropil, likely reflecting SOD2 downregulation in astrocytes, oligodendrocytes, macrophages, and vascular cells (Ruetzler et al., 2001) could prove beneficial for the neurogliovascular unit that mediates neurovascular coupling (Hamel, 2006; Haydon and Carmignoto, 2006). Indeed, the hemodynamic response to sensory stimulation was normalized in pioglitazone-treated mice (see below).

\section{Cerebrovascular dysfunction and amyloidosis}

NAC and pioglitazone had no effect on total soluble $A \beta$ and/or $\mathrm{A} \beta_{1-40}$ and $\mathrm{A} \beta_{1-42}$, nor did they reduce insoluble $\mathrm{A} \beta$ species or plaque load, indicating that therapy initiated at this late stage of the pathology did not counter amyloidosis and $\mathrm{A} \beta$ deposition. Our findings fully agree with those of Yan et al. (2003), who found no change in levels of $\mathrm{A} \beta_{1-42}$ or plaque burden in 15month-old Tg2576 APP mice treated for 16 weeks with a comparable dose of pioglitazone, but are at variance with the beneficial effect reported by Heneka et al. (2005) in 10-month-old APPV717I mice treated for only $7 \mathrm{~d}$ with a higher dose $(40 \mathrm{mg} /$ $\mathrm{kg} / \mathrm{d}$ ). Whether model-specific differences in soluble $\mathrm{A} \beta$ levels or plaque burden account for these discrepancies, the normalization of both cerebrovascular reactivity in isolated arteries and stimulus-evoked CBF response in vivo observed here unambigu- ously demonstrate that functional recovery can be achieved in the amyloid-burdened brain. Together with a recent report in aged Nox2-null APP mice showing preserved cerebrovascular function without reduction in brain $\mathrm{A} \beta$ levels or plaques (Park et al., 2008), our findings become highly relevant for AD patients, as therapeutic intervention could preserve perfusion despite high amyloid burdens.

\section{Astrocytic and neuronal AD markers}

Pioglitazone decreased astrocyte activation, consistent with the ability of PPAR $\gamma$ agonists to diminish proinflammatory gene expression and cytokine release (Heneka et al., 2005, 2007). Reduced neuroinflammation coupled with attenuated oxidative stress, as reflected by the SOD2 downregulation in the cortical neuropil, may promote a favorable environment for neurons and allow them to resume ChAT synthesis to levels compatible with immunodetection. Such a scenario is plausible in the APP mouse brain that does not feature loss of cholinergic neuronal perikarya (Aucoin et al., 2005), and in light of the recovery of cortical cholinergic varicosities in aged rats after nerve growth factor treatment (Cardoso et al., 2006). Moreover, counteracting plaqueassociated astrocyte activation and oxidative stress (Wyss-Coray et al., 2003; Aucoin et al., 2005; present study) may account for the ability of pioglitazone to decrease the proportion of plaques 

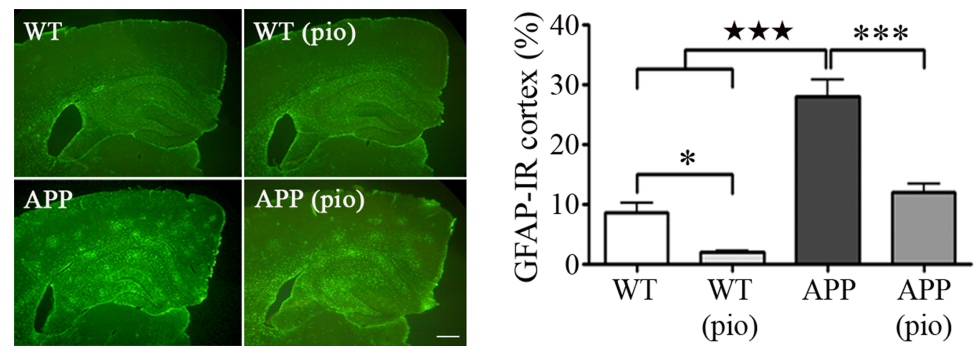

Figure 3. Pioglitazone attenuates astrocyte activation. Increased GFAP immunoreactivity appeared as islets of activation in the cortex and a continuous stretch of activated tissue in the hippocampus of APP mice relative to wild-type littermates ( ${ }^{\star \star \star} p<$ 0.001). Although NAC treatment (data not shown) had no effect, pioglitazone (pio) significantly decreased the percentage GFAP-immunoreactive (IR) cortical area in both treated wild-type and APP mice $\left({ }^{*} p<0.05,{ }^{* * *} p<0.001\right)(n=4-5$ mice/ group). Scale bar, $300 \mu \mathrm{m}$. Error bars represent SEM.

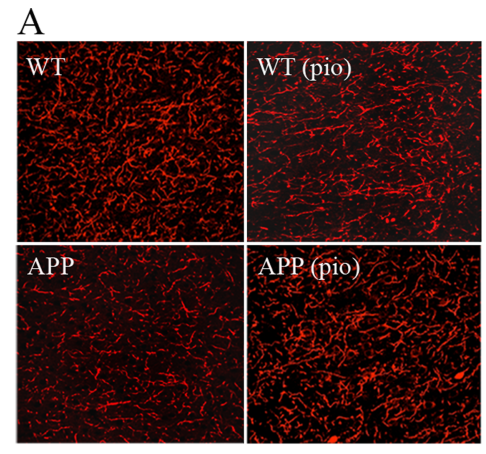

B

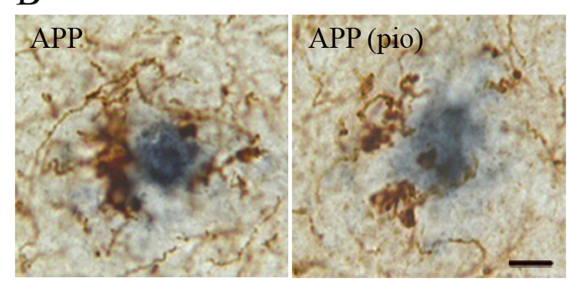

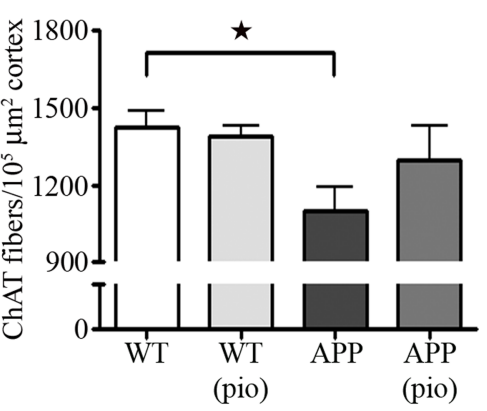

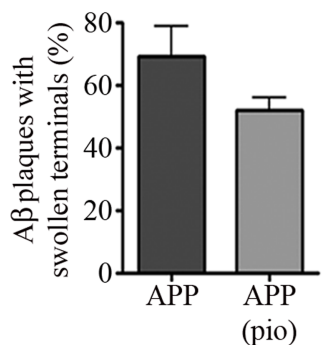

Figure 4. Effect of pioglitazone on the cholinergic innervation. $\boldsymbol{A}$, The significant decrease in the number of ChAT fibers detected in APP mice compared with wild-type littermates ( ${ }^{\star} p<0.05$, Student's $t$ test) was improved by pioglitazone (pio), although not significantly, but not by NAC (data not shown). Data are from one representative experiment of three independent ones. $\boldsymbol{B}$, Pioglitazone also slightly attenuated $A \beta$ plaque-associated neurotoxicity as a smaller percentage of $A \beta_{1-42}$-positive plaques (gray) were surrounded by dystrophic ChAT terminals (brown) ( $n=3-5$ mice/group). Scale bar, $10 \mu \mathrm{m}$. Error bars represent SEM.

featuring dystrophic ChAT terminals. Similar benefits of PPAR $\gamma$ agonist therapy on oxidative stress and cholinergic innervation were reported in streptozotocin-induced memory-impaired rats (de la Monte et al., 2006). However, the residual neuronal mitochondrial oxidative stress, revealed by the persistently increased neuronal SOD2 immunostaining, could contribute to the lasting cognitive deficit in treated APP mice through decreased ATP production and compromised neuronal homeostasis (Dröge and Schipper, 2007).

\section{Brain perfusion, glucose metabolism, and cognition}

Pioglitazone improved the increase in glucose use elicited by somatosensory activation in APP mice, consistent with its ability to restore glucose uptake in brain slices of memory-impaired rats (Pathan et al., 2006). Furthermore, pioglitazone normalized the functional hyperemic response, which correlated in individual animals with enhanced reactivity of isolated arteries. These findings are exceptionally valuable to $\mathrm{AD}$, where decreased glucose metabolism (Silverman et al., 2001; Mosconi et al., 2004) and chronic hypoperfusion (de la Torre, 2004; Zlokovic, 2005) occur prematurely. Indeed, decreased glucose and oxygen availability increase $\mathrm{AD}$ risk in susceptible populations (Kalaria, 2000) or worsen cognitive deterioration in the already compromised $\mathrm{AD}$ brain, as highlighted recently in APP mice that displayed exacerbated memory deficits after hypoxic episodes (Sun et al., 2006). Whether neuronal deficits account for decreased oxygen and glucose demand or early decreases in CBF and CGU synergize to impair neuronal function, our results demonstrate that normalizing cerebral perfusion and metabolism in the $\mathrm{A} \beta$ burdened brain is a viable strategy.

Yet, despite full recovery of cerebrovascular function and glucose uptake, pioglitazone failed to restore memory. Although surprising at first, this may be explained by the fact that animals were treated for a short time, at a very late stage of a pathology that results in cognitive deficits before 7 months of age (Palop et al., 2003) and, possibly, by stringent conditions in the water maze, where mice did not receive visible-platform pretraining. Although improved cognitive performance in the Y maze has been reported despite high levels of soluble $\mathrm{A} \beta_{1-40}$ and $\mathrm{A} \beta_{1-42}$ (Park et al., 2008), the persistent deficit seen here in the Morris water maze could be explained by the unforgiving nature of this test, the use of APP mice bearing two mutations rather than the single Swedish mutation of Tg2576 mice and/or the ongoing presence of toxic forms of soluble $A \beta$ in the brain of pioglitazone-treated animals (Lesné et al., 2006). Indeed, $A \beta$ clearance with passive immunization protocols significantly improved performance of 20-month-old Tg2576 mice in the radial-arm water maze (Wilcock et al., 2006). Still, the possibility to fully restore cerebrovascular function despite high amyloid levels is highly pertinent for $\mathrm{AD}$ patients while they await the results of future human immunization trials or new therapies. In light of the ability of rosiglitazone to attenuate deficits after 4 month treatment in 9-month-old Tg2576 mice in the radial-arm maze (Pedersen et al., 2006) and to improve memory in a subset of mild to moderate AD patients (Watson et al., 2005; Risner et al., 2006), we suggest that earlier and longer pioglitazone treatment will likely exert benefits on cognition, as demonstrated in rats with streptozotocin inducedmemory impairment (Pathan et al., 2006). Notably, in addition to its benefit on cerebrovascular function, pioglitazone offers the added advantage over rosiglitazone of crossing the blood-brain barrier, hence, acting on affected cholinergic neurons and glial cells (de la Monte et al., 2006; present study).

\section{Conclusions}

Our study demonstrates that the deleterious effects of soluble A $\beta$ on the brain microcirculation can be overridden by therapies that 
antagonize $\mathrm{A} \beta$-induced oxidative stress. Although antioxidant therapy has proven beneficial in various animal models of cognitive decline (Liu et al., 2003), including APP mice (Farr et al., 2003; Park et al., 2008), it has been relatively ineffective in the multifactorial process culminating in AD (Adair et al., 2001; Petersen et al., 2005). Our results and evidence from both $\mathrm{AD}$ animal models and patients strongly point to pioglitazone as a most promising therapy against chronic hypoperfusion and decreased glucose metabolism in $\mathrm{AD}$, with additional benefits on astroglial and cholinergic alterations that characterize this devastating disease.

\section{References}

Adair JC, Knoefel JE, Morgan N (2001) Controlled trial of $\mathrm{N}$-acetylcysteine for patients with probable Alzheimer's disease. Neurology 57:1515-1517.

Andresen J, Shafi NI, Bryan RM Jr (2006) Endothelial influences on cerebrovascular tone. J Appl Physiol 100:318-327.

Aucoin JS, Jiang P, Aznavour N, Tong XK, Buttini M, Descarries L, Hamel E (2005) Selective cholinergic denervation, independent of oxidative stress, in a mouse model of Alzheimer's disease. Neuroscience 132:73-86.

Auld DS, Kornecook TJ, Bastianetto S, Quirion R (2002) Alzheimer's disease and the basal forebrain cholinergic system: relations to betaamyloid peptides, cognition, and treatment strategies. Prog Neurobiol 68:209-245.

Bagi Z, Koller A, Kaley G (2004) PPAR $\gamma$ activation, by reducing oxidative stress, increases NO bioavailability in coronary arterioles of mice with Type 2 diabetes. Am J Physiol Heart Circ Physiol 286:H742-H748.

Beckmann N, Schuler A, Mueggler T, Meyer EP, Wiederhold KH, Staufenbiel M, Krucker T (2003) Age-dependent cerebrovascular abnormalities and blood flow disturbances in APP23 mice modeling Alzheimer's disease. J Neurosci 23:8453-8459.

Brouillette J, Quirion R (2008) The common environmental pollutant dioxin-induced memory deficits by altering estrogen pathways and a major route of retinol transport involving transthyretin. Neurotoxicology 29:318-327.

Cabassi A, Dumont EC, Girouard H, Bouchard JF, Le Jossec M, Lamontagne D, Besner JG, de Champlain J (2001) Effects of chronic N-acetylcysteine treatment on the actions of peroxynitrite on aortic vascular reactivity in hypertensive rats. J Hypertens 19:1233-1244.

Cardoso A, Paula-Barbosa MM, Lukoyanov NV (2006) Reduced density of neuropeptide $\mathrm{Y}$ neurons in the somatosensory cortex of old male and female rats: relation to cholinergic depletion and recovery after nerve growth factor treatment. Neuroscience 137:937-948.

Chen XJ, Kovacevic N, Lobaugh NJ, Sled JG, Henkelman RM, Henderson JT (2006) Neuroanatomical differences between mouse strains as shown by high-resolution 3D MRI. Neuroimage 29:99-105.

Cummings JL (2004) Alzheimer's disease. N Engl J Med 351:59-67.

de la Monte SM, Tong M, Lester-Coll N, Plater M Jr, Wands JR (2006) Therapeutic rescue of neurodegeneration in experimental type 3 diabetes: relevance to Alzheimer's disease. J Alzheimer's Dis 10:89-109.

de la Torre JC (2004) Is Alzheimer's disease a neurodegenerative or a vascular disorder? Data, dogma, and dialectics. Lancet Neurol 3:184-190.

de la Torre JC, Fortin T, Park GA, Butler KS, Kozlowski P, Pappas BA, de Socarraz H, Saunders JK, Richard MT (1992) Chronic cerebrovascular
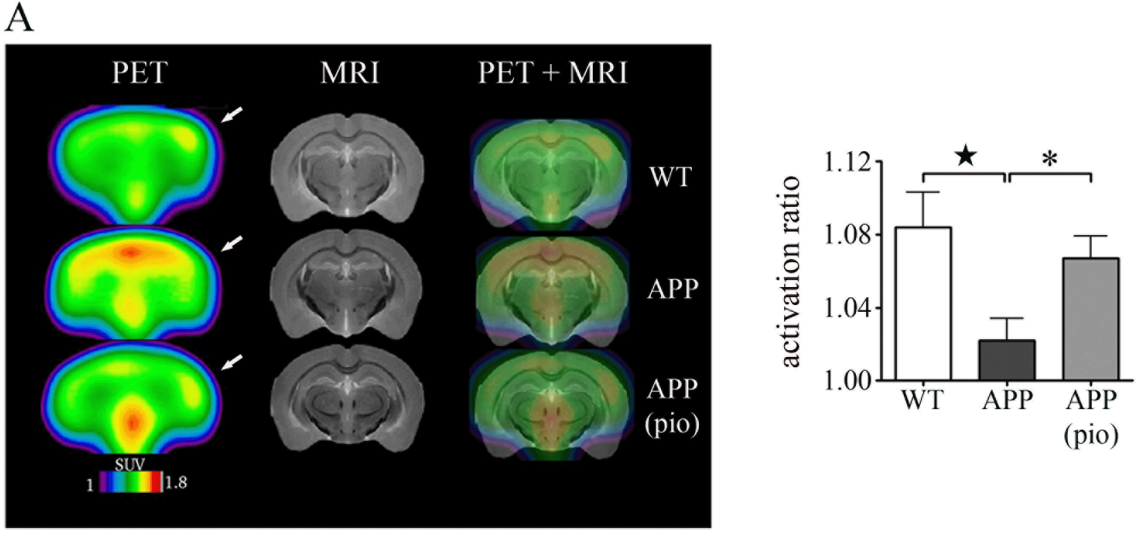

(pio)

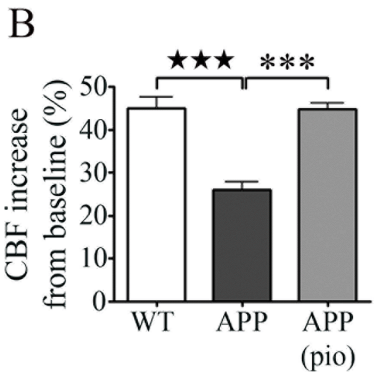

C
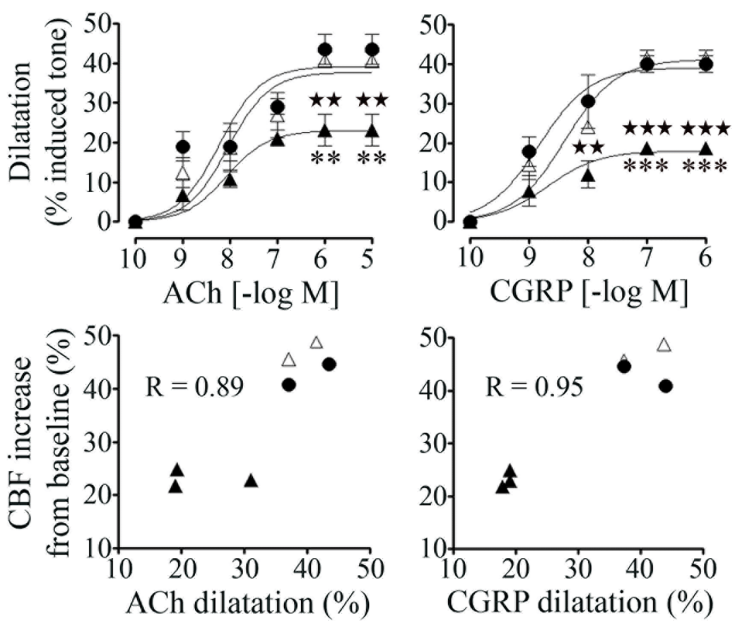

Figure 5. Pioglitazone normalizes the CGU and CBF responses evoked in vivo by increased neuronal activity after whisker ulation (bottom, arrows; traces: green, wild-type; blue, APP, red, treated APP mice) as measured by laser Doppler lowmetry ( $n=4-7$ mice/group). $C$, In a subset of mice (3 per group), pioglitazone completely normalized impaired reactivity to 0.001 , untreated APP $(\boldsymbol{\Delta})$ versus wild-type $(\bullet)$ mice; ${ }^{* *} p<0.01$, ${ }^{* * *} p<0.001$, treated $(\triangle)$ versus untreated APP mice. $R$, Pearson correlation coefficient. Error bars represent SEM.

insufficiency induces dementia-like deficits in aged rats. Brain Res 582:186-195.

DeWitt DS, Mathew BP, Chaisson JM, Prough DS (2001) Peroxynitrite reduces vasodilatory responses to reduced intravascular pressure, calcitonin gene-related peptide, and cromakalim in isolated middle cerebral arteries. J Cereb Blood Flow Metab 21:253-261.

Diep QN, El Mabrouk M, Cohn JS, Endemann D, Amiri F, Virdis A, Neves MF, Schiffrin EL (2002) Structure, endothelial function, cell growth, and inflammation in blood vessels of angiotensin II-infused rats: role of peroxisome proliferator-activated receptor- $\gamma$. Circulation 105: $2296-2302$.

Dröge W, Schipper HM (2007) Oxidative stress and aberrant signaling in aging and cognitive decline. Aging Cell 6:361-370.

Elder GA, Cho JY, English DF, Franciosi S, Schmeidler J, Sosa MA, Gasperi RD, Fisher EA, Mathews PM, Haroutunian V, Buxbaum JD (2007) Elevated plasma cholesterol does not affect brain $\mathrm{A} \beta$ in mice lacking the low-density lipoprotein receptor. J Neurochem 102:1220-1231.

Farr SA, Poon F, Dogrukol-AK D, Drake J, Banks WA, Eyerman E, Butterfield DA, Morley JE (2003) The antioxidants $\alpha$-lipoic acid and 

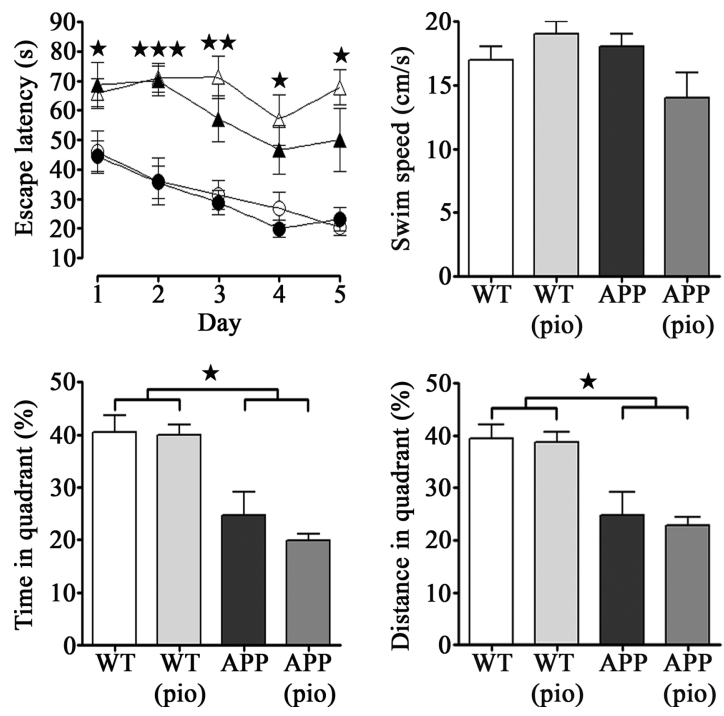

Figure 6. Pioglitazone did not reverse impaired performance in the spatial memory-based Morris water maze test. APP mice $(\boldsymbol{\Delta})$ displayed longer latencies to reach a hidden platform compared with wild-type littermates $(\mathbf{O})$, as well as decreased time and traveling distance in the target quadrant during the removed-platform probe trial. Pioglitazone (pio) did not improve performance of either treated $\operatorname{APP}(\triangle)$ or wild-type $(O)$ mice. Swim speeds were comparable among groups $\left({ }^{\star} p<0.05,{ }^{\star \star} p<0.01,{ }^{\star \star \star} p<0.001\right)(n=4-10$ mice/group $)$. Error bars represent SEM.

$\mathrm{N}$-acetylcysteine reverse memory impairment and brain oxidative stress in aged SAMP8 mice. J Neurochem 84:1173-1183.

Girouard H, Iadecola C (2006) Neurovascular coupling in the normal brain and in hypertension, stroke, and Alzheimer disease. J Appl Physiol 100:328-335.

Hamel E (2004) Cholinergic modulation of the cortical microvascular bed. Prog Brain Res 145:171-178.

Hamel E (2006) Perivascular nerves and the regulation of cerebrovascular tone. J Appl Physiol 100:1059-1064.

Hamel E, Nicolakakis N, Aboulkassim T, Ongali B, Tong XK (2008) Oxidative stress and cerebrovascular dysfunction in mouse models of Alzheimer's disease. Exp Physiol 93:116-120.

Haydon PG, Carmignoto G (2006) Astrocyte control of synaptic transmission and neurovascular coupling. Physiol Rev 86:1009-1031.

Heneka MT, Sastre M, Dumitrescu-Ozimek L, Hanke A, Dewachter I, Kuiperi C, O'Banion K, Klockgether T, Van Leuven F, Landreth GE (2005) Acute treatment with the PPAR $\gamma$ agonist pioglitazone and ibuprofen reduces glial inflammation and A $\beta 1-42$ levels in APPV717I transgenic mice. Brain 128:1442-1453.

Heneka MT, Landreth GE, Hüll M (2007) Drug insight: effects mediated by peroxisome proliferator-activated receptor- $\gamma$ in CNS disorders. Nat Clin Pract Neurol 3:496-504.

Hermann DM, Kilic E, Hata R, Hossmann KA, Mies G (2001) Relationship between metabolic dysfunctions, gene responses and delayed cell death after mild focal cerebral ischemia in mice. Neuroscience 104:947-955.

Hwang J, Kleinhenz DJ, Rupnow HL, Campbell AG, Thulé PM, Sutliff RL, Hart CM (2007) The PPAR $\gamma$ ligand, rosiglitazone, reduces vascular oxidative stress and NADPH oxidase expression in diabetic mice. Vasc Pharmacol 46:456-462.

Iadecola C, Zhang F, Niwa K, Eckman C, Turner SK, Fischer E, Younkin S, Borchelt DR, Hsiao KK, Carlson GA (1999) SOD1 rescues cerebral endothelial dysfunction in mice overexpressing amyloid precursor protein. Nat Neurosci 2:157-161.

Inoue I, Goto S, Matsunaga T, Nakajima T, Awata T, Hokari S, Komoda T, Katayama S (2001) The ligands/activators for peroxisome proliferatoractivated receptor $\alpha(\operatorname{PPAR} \alpha)$ and PPAR $\gamma$ increase $\mathrm{Cu}^{2+}, \mathrm{Zn}^{2+}$. superoxide dismutase and decrease $\mathrm{p} 22^{\text {phox }}$ message expression in primary endothelial cells. Metabolism 50:3-11.

Kalaria RN (2000) The role of cerebral ischemia in Alzheimer's disease. Neurobiol Aging 21:321-330.

Kitazono T, Heistad DD, Faraci FM (1993) Role of ATP-sensitive $\mathrm{K}^{+}$chan- nels in CGRP-induced dilatation of basilar artery in vivo. Am J Physiol 265:H581-H585.

Kornblum HI, Araujo DM, Annala AJ, Tatsukawa KJ, Phelps ME, Cherry SR (2000) In vivo imaging of neuronal activation and plasticity in the rat brain by high resolution positron emission tomography (microPET). Nat Biotechnol 18:655-660.

Lesné S, Koh MT, Kotilinek L, Kayed R, Glabe CG, Yang A, Gallagher M, Ashe $\mathrm{KH}$ (2006) A specific amyloid- $\beta$ protein assembly in the brain impairs memory. Nature 440:352-357.

Liu R, Liu IY, Bi X, Thompson RF, Doctrow SR, Malfroy B, Baudry M (2003) Reversal of age-related learning deficits and brain oxidative stress in mice with superoxide dismutase/catalase mimetics. Proc Natl Acad Sci U S A 100:8526-8531.

Martens FM, Visseren FL, de Koning EJ, Rabelink TJ (2005) Short-term pioglitazone treatment improves vascular function irrespective of metabolic changes in patients with type 2 diabetes. J Cardiovasc Pharmacol 46:773-778.

Mayhan WG, Arrick DM, Sharpe GM, Patel KP, Sun H (2006) Inhibition of $\mathrm{NAD}(\mathrm{P}) \mathrm{H}$ oxidase alleviates impaired NOS-dependent responses of pial arterioles in type 1 diabetes mellitus. Microcirculation 13:567-575.

Morris R (1984) Developments of a water-maze procedure for studying spatial learning in the rat. J Neurosci Methods 11:47-60.

Moosavi M, Naghdi N, Maghsoudi N, Zahedi Asl S (2007) Insulin protects against stress-induced impairments in water maze performance. Behav Brain Res 176:230-236.

Mosconi L, Perani D, Sorbi S, Herholz K, Nacmias B, Holthoff V, Salmon E, Baron J-C, De Cristofaro MT, Padovani A, Borroni B, Franceschi M, Bracco L, Pupi A (2004) MCI conversion to dementia and the APOE genotype: a prediction study with FDG-PET. Neurology 63:2332-2340.

Mucke L, Masliah E, Yu GQ, Mallory M, Rockenstein EM, Tatsuno G, Hu K, Kholodenko D, Johnson-Wood K, McConlogue L (2000) High-level neuronal expression of $A \beta_{1-42}$ in wild-type human amyloid protein precursor transgenic mice: synaptotoxicity without plaque formation. J Neurosci 20:4050-4058

Niwa K, Younkin L, Ebeling C, Turner SK, Westaway D, Younkin S, Ashe KH, Carlson GA, Iadecola C (2000) Abeta 1-40-related reduction in functional hyperemia in mouse neocortex during somatosensory activation. Proc Natl Acad Sci U S A 97:9735-9740.

Niwa K, Kazama K, Younkin L, Younkin SG, Carlson GA, Iadecola C (2002) Cerebrovascular autoregulation is profoundly impaired in mice overexpressing amyloid precursor protein. Am J Physiol Heart Circ Physiol 283:H315-H323.

Palop JJ, Jones B, Kekonius L, Chin J, Yu GQ, Raber J, Masliah E, Mucke L (2003) Neuronal depletion of calcium-dependent proteins in the dentate gyrus is tightly linked to Alzheimer's disease-related cognitive deficits. Proc Natl Acad Sci U S A 100:9572-9577.

Park L, Anrather J, Zhou P, Frys K, Pitstick R, Younkin S, Carlson GA, Iadecola C (2005) NADPH oxidase-derived reactive oxygen species mediate the cerebrovascular dysfunction induced by the amyloid- $\beta$ peptide. J Neurosci 25:1769-1777.

Park L, Zhou P, Pitstick R, Capone C, Anrather J, Norris EH, Younkin L, Younkin S, Carlson G, McEwen BS, Iadecola C (2008) Nox2-derived radicals contribute to neurovascular and behavioral dysfunction in mice overexpressing the amyloid precursor protein. Proc Natl Acad Sci U S A 105:1347-1352.

Pathan AR, Viswanad B, Sonkusare SK, Ramarao P (2006) Chronic administration of pioglitazone attenuates intracerebroventricular streptozotocin induced-memory impairment in rats. Life Sci 79:2209-2216.

Pedersen WA, McMillan PJ, Kulstad JJ, Leverenz JB, Craft S, Haynatzki GR (2006) Rosiglitazone attenuates learning and memory deficits in Tg2576 Alzheimer mice. Exp Neurol 199:265-273.

Petersen RC, Thomas RG, Grundman M, Bennett D, Doody R, Ferris S, Galasko D, Jin S, Kaye J, Levey A, Pfeiffer E, Sano M, van Dyck CH, Thal LJ (2005) Vitamin $\mathrm{E}$ and donepezil for the treatment of mild cognitive impairment. N Engl J Med 352:2379-2388.

Risner ME, Saunders AM, Altman JF, Ormandy GC, Craft S, Foley IM, Zvartau-Hind ME, Hosford DA, Roses AD (2006) Efficacy of rosiglitazone in a genetically defined population with mild-to-moderate Alzheimer's disease. Pharmacogenomics J 6:246-254.

Ruetzler CA, Furuya K, Takeda H, Hallenbeck JM (2001) Brain vessels normally undergo cyclic activation and inactivation: evidence from tumor necrosis factor- $\alpha$, heme oxygenase-1, and manganese superoxide dis- 
mutase immunostaining of vessels and perivascular brain cells. J Cereb Blood Flow Metab 21:244-252.

Ruitenberg A, den Heijer T, Bakker SL, van Swieten JC, Koudstaal PJ, Hofman A, Breteler MM (2005) Cerebral hypoperfusion and clinical onset of dementia: the Rotterdam study. Ann Neurol 57:789-794.

Schnackenberg CG, Wilcox CS (1999) Two-week administration of Tempol attenuates both hypertension and renal excretion of 8-iso prostaglandin $\mathrm{F}_{2 \alpha}$. Hypertension 33:424-428.

Schnackenberg CG, Wilcox CS (2001) The SOD mimetic tempol restores vasodilation in afferent arterioles of experimental diabetes. Kidney Int 59:1859-1864.

Silverman DH, Small GW, Chang CY, Lu CS, Kung De Aburto MA, Chen W, Czernin J, Rapoport SI, Pietrini P, Alexander GE, Schapiro MB, Jagust WJ, Hoffman JM, Welsh-Bohmer KA, Alavi A, Clark CM, Salmon E, de Leon MJ, Mielke R, Cummings JL, et al. (2001) Positron emission tomography in evaluation of dementia: regional brain metabolism and long-term outcome. JAMA 286:2120-2127.

Sun X, He G, Qing H, Zhou W, Dobie F, Cai F, Staufenbiel M, Huang LE, Song W (2006) Hypoxia facilitates Alzheimer's disease pathogenesis by up-regulating BACE1 gene expression. Proc Natl Acad Sci USA 103:18727-18732.

Tong XK, Hamel E (1999) Regional cholinergic denervation of cortical microvessels and nitric oxide synthase-containing neurons in Alzheimer's disease. Neuroscience 92:163-175.

Tong XK, Nicolakakis N, Kocharyan A, Hamel E (2005) Vascular remodeling versus amyloid beta-induced oxidative stress in the cerebrovascular dysfunctions associated with Alzheimer's disease. J Neurosci 25:11165-11174.

Watson GS, Cholerton BA, Reger MA, Baker LD, Plymate SR, Asthana S, Fishel MA, Kulstad JJ, Green PS, Cook DG, Kahn SE, Keeling ML, Craft S (2005) Preserved cognition in patients with early Alzheimer disease and amnestic mild cognitive impairment during treatment with rosiglitazone: a preliminary study. Am J Geriatr Psychiatry 13:950-958.

Wilcock DM, Alamed J, Gottschall PE, Grimm J, Rosenthal A, Pons J, Ronan V, Symmonds K, Gordon MN, Morgan D (2006) Deglycosylated antiamyloid- $\beta$ antibodies eliminate cognitive deficits and reduce parenchymal amyloid with minimal vascular consequences in aged amyloid precursor protein transgenic mice. J Neurosci 26:5340-5346.

Wong GH, Goeddel DV (1988) Induction of manganous superoxide dismutase by tumor necrosis factor: Possible protective mechanism. Science 242:941-944.

Wyss-Coray T, Loike JD, Brionne TC, Lu E, Anankov R, Yan F, Silverstein SC, Husemann J (2003) Adult mouse astrocytes degrade amyloid- $\beta$ in vitro and in situ. Nat Med 9:453-457.

Yan Q, Zhang J, Liu H, Babu-Khan S, Vassar R, Biere AL, Citron M, Landreth G (2003) Anti- inflammatory drug therapy alters $\beta$-amyloid processing and deposition in an animal model of Alzheimer's disease. J Neurosci 23:7504-7509.

Zlokovic BV (2005) Neurovascular mechanisms of Alzheimer's neurodegeneration. Trends Neurosci 28:202-208.

Zonta M, Angulo MC, Gobbo S, Rosengarten B, Hossmann KA, Pozzan T, Carmignoto G (2003) Neuron-to-astrocyte signaling is central to the dynamic control of brain microcirculation. Nat Neurosci 6:43-50. 